\title{
The Taste That Kills!
}

\author{
Anjali K Gohel* \\ R\&D Trainee, Hindustan Unilever Limited, India \\ *Corresponding author: Anjali K Gohel, R\&D Trainee, Hindustan Unilever Limited, India
}

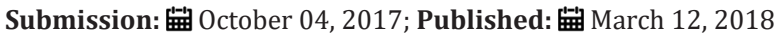

\section{Opinion}

The sensation of flavor perceived by taste buds in the mouth and throat on contact with a substance is defined as taste. The primary role of taste enhancers is to increase the delicacy of food, give an identity to the product and a lasting memory. However, there is a darker side to the same picture without which the true definition of taste enhancers is incomplete. Excitotoxins are one of the taste enhancers found in abundance in many natural as well as artificial food products. These agents cause certain neurons in brain to become over stimulated and fire continuously until they exhaust and die, hence the term - "excito-toxins". This overstimulation distorts the normal chemical balance in the brain necessary for its proper functioning. The cumulative effect of these agents can lead to dreadful neurodegenerative disorders viz Lou Gehrig's disease, Alzheimer's disease, Parkinson's syndrome, hungton's syndrome etc.

Excitotoxins include Monosodium glutamate (MSG) commonly known as Aji-No-Moto, hydrolyzed vegetable protein, aspartame (sold as Nutra Sweet) and cystein. Glutamate as taste enhancer was discovered by Prof. Kikunae Ikeda of Tokyo Imperial University in 1908 by aqueous extraction and crystallization of seaweed laminaria. The use of MSG after this increased rapidly worldwide. The taste of glutamate as 'umami', coined by him became an official scientific term in 1985 and thereafter, was accepted as 5th basic taste in addition to sweet, sour, salty and bitter. Glutamate is a neurotransmitter and is involved in most aspects of normal brain function including cognition, memory and learning. However, excess glutamate release can lead to excitotoxicity causing cell death.

The food items rich in umami taste includes fish, vegetables like ripe tomatoes, spinach, Chinese cabbage, green tea, fermented products like cheese, soy sause, packed food items like salad dressings, chips, soyabean milk, readymix soups, fastfoods, yeast extracts etc. From 1969, MSG was voluntarily removed from baby food items after studying its hazardous effects on animals. In 1995, FASEB on behalf of USFDA concluded MSG as safe when consumed at customary level. Neutralizing factors to excitotoxin poisoning in the brain appear to include Vitamin C and Vitamin E. Other antioxidant helpers are beta carotene, Vitamin K, Vitamin D, Vitamin A and the minerals magnesium, chromium, zinc and selenium. Apart from these kitchen remedies, there are products provided by Biotics Research Corporation which include MG-ZYME, E-MULSION 200, BIO-C-PLUS 1000.

An alternate and safe option of taste enhancer as against MSG and NutraSweet could be Stevia rebaudiana, a South American shrub. The leaves of this plant have been used as sweeteners for generations and according to a new Indian study published in the Journal of Agricultural and Food Chemistry indicate that leaf extract of this is potential source of natural antioxidants. Much of importance is being given on taste enhancers today so as to catch up the interest of the consumers and thereby, promote the sales of the product. This is death by profit margin, because the research is clear regarding the damaging effects of these additives.
Creative Commons Attribution 4.0 International License

For possible submissions Click Here Submit Article

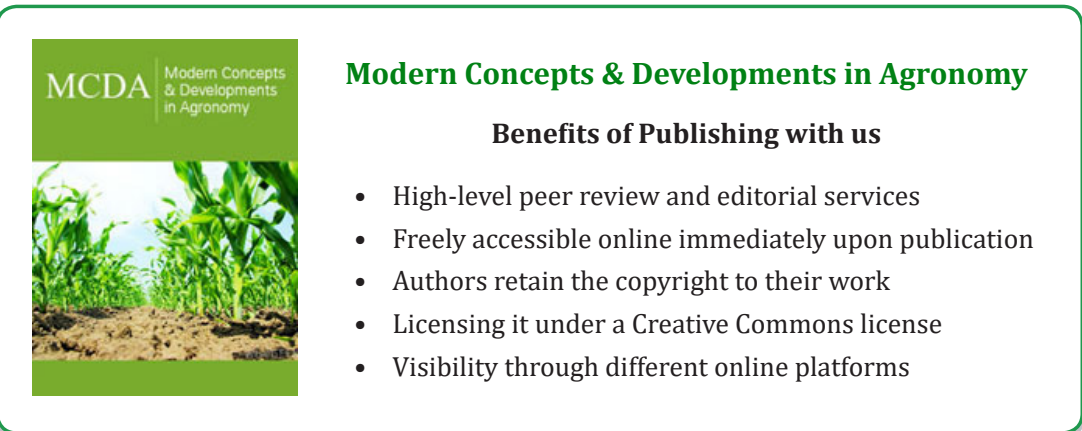

